Artigo de Revisão e/ou Atualização de Literatura

\title{
Terapia ocupacional e Paulo Freire: uma revisão de escopo
}

\section{Occupational therapy and Paulo Freire: a scoping review}

\author{
Magno Nunes Farias ${ }^{\mathrm{a}, \mathrm{b}}$ (D), Roseli Esquerdo Lopes ${ }^{\mathrm{b}}$ (D) \\ ${ }^{a}$ Universidade de Brasília - UnB, Brasília, DF, Brasil. \\ bUniversidade Federal de São Carlos - UFSCar, São Carlos, SP, Brasil.
}

Como citar: Farias, M. N., \& Lopes, R. E. (2022). Terapia ocupacional e Paulo Freire: uma revisão de escopo. Cadernos Brasileiros de Terapia Ocupacional, 30, e2958. https://doi.org/10.1590/2526-8910.ctoAR22412958

\begin{abstract}
$\underline{\text { Resumo }}$
Introduçáo: $\mathrm{O}$ referencial teórico e o aporte metodológico trazidos pelas obras de Paulo Freire vêm se espraiando por distintas áreas, inclusive na terapia ocupacional. Objetivo: Apreender como o referencial freireano vem sendo utilizado em publicaçóes acadêmicas da terapia ocupacional, reunindo e analisando essa literatura, para identificar eixos temáticos e lacunas presentes. Método: Revisão de escopo, com levantamento de publicaçóes nas bases de dados CINAHL, Scopus e Web of Science, focalizando artigos acadêmicos que referenciam explicitamente Paulo Freire, num período que, sem recorte inicial, foi até abril de 2020, tendo sido incluídos todos os artigos que referenciavam pelo menos uma obra do autor. Uma planilha desenvolvida no programa Microsoft Excel ${ }^{\top}$ reuniu os dados gerais dos artigos, cujos conteúdos foram agrupados, sintetizados e analisados a partir de conjuntos temáticos significativos. Resultados: Foram identificados 56 artigos, publicados entre 1993 e abril de 2020. A obra de Freire vem sendo utilizada em publicaçóes acadêmicas da terapia ocupacional, destacando-se o livro "Pedagogia do Oprimido" e as categorias Diálogo/Dialógica e Conscientização/Consciência crítica/política. Foram definidos e discutidos três conjuntos temáticos: $33(58,9 \%)$ artigos que utilizam o referencial freireano para o pensar/fazer da terapia ocupacional; $10(17,8 \%)$ em que ele parametriza a pesquisa na área; $13(23,2 \%)$ cujas análises e proposiçóes envolvendo a formação de terapeutas ocupacionais tomam-no como aporte. Conclusáo: Paulo Freire informa de diversas maneiras a terapia ocupacional, em prol de uma práxis para a transformaçáo social, embora, em boa parte das vezes, as formulaçôes freireanas náo sejam o centro dos esforços de elaboração reflexiva.
\end{abstract}

Palavras-chave: Mudança Social, Problemas Sociais, Conscientização, Opressão Social, Terapia Ocupacional.

\section{$\underline{\text { Abstract }}$}

Introduction: Paulo Freire's theoretical references and methodological propositions are spread over different study areas, including occupational therapy. Objective: To understand how the Freirean framework has been used in academic publications on 
occupational therapy, gathering and analyzing this literature to identify thematic axes and gaps. Method: A scoping review conducted through an open-period search until April 2020 for all academic articles that explicitly referenced at least one work by Paulo Freire. Data from the retrieved articles were gathered, synthesized, and organized on a Microsoft Excel ${ }^{\circ}$ spreadsheet and then analyzed from significant thematic axes. Results: The search identified 56 articles published between 1993 and April 2020. Freire's work has been used in occupational therapy academic publications, with emphasis on the book "Pedagogy of the Oppressed" and the concepts of Dialogueldialogics and Critical and political consciousness/conscientization. Three thematic axes were defined and discussed: 33 (58.9\%) studies used Paulo Freire as a theoretical-methodological framework for thinking/practicing occupational therapy, $10(17.8 \%)$ used Freire as a framework to assist with research in the area, and 13 (23.2\%) used Freire's contributions in analyses and propositions involving the education of occupational therapists. Conclusions: Paulo Freire contributes to occupational therapy in different ways, favoring a praxis for social transformation; however, in most cases, the Freirean propositions are not the center of reflexive development efforts.

Keywords: Social Change, Social Problems, Conscientization, Social Oppression, Occupational Therapy.

\section{Introduçáo}

Paulo Reglus Neves Freire nasceu no dia 19 de setembro de 1921, em Recife, Pernambuco, Nordeste do Brasil. Segundo Gadotti (1996), desde a adolescência, Freire se engajou em processos de formação de jovens e adultos trabalhadores e, mais tarde, a partir dos anos de 1950, começou a pensar e propor formas não tradicionais e diferenciadas de se fazer pedagogia junto aos sujeitos, que associassem pedagogia, política, diálogo, conscientização e problematização, tendo como eixo central a concepçáo de educação como prática da liberdade. Ou seja, uma educação que "[...] visa à libertação, à transformação radical da realidade, para melhorá-la, para torná-la mais humana, para permitir que os homens e as mulheres sejam reconhecidos como sujeitos da sua história e não como objetos" (Gadotti, 1996, p. 81), superando a condiçáo de oprimidos.

Durante sua trajetória, envolveu-se em diversos projetos de educação popular, que se iniciaram em 1960, no contexto de um país onde 50\% da populaçáo era analfabeta. Com base naquelas elaboraçóes em torno de uma pedagogia náo tradicional e em suas concepçóes políticas, suas primeiras experiências se deram em 1963, em Angicos, município do estado do Rio Grande do Norte - Brasil, junto a 300 trabalhadores, que foram alfabetizados por meio dos círculos de cultura ${ }^{1}$.

Com a grande repercussão desse movimento de alfabetização e cultura formulado por Paulo Freire, em 1964, ele foi nomeado Coordenador do Programa Nacional de Alfabetização, vinculado ao Ministério da Educação. Os planos eram que, nesse mesmo

${ }^{1} \mathrm{O}$ círculo de cultura é uma estratégia formulada por Freire para uma prática educativa conscientizadora. A partir do diálogo em roda e do exercício com a palavra, inclusive escrita, objetiva-se que os sujeitos em colaboração problematizem o mundo, desvelando suas contradiçôes e, com a consciência e reflexão sobre elas e sobre si mesmo, elaborem/pensem formas para superar estruturas de dominação, tomando-se o estar no mundo e com o mundo, em um processo de práxis, humanização e emancipação (Fiori, 1987). 
ano, fossem criados 20 mil círculos de cultura, para atingir dois milhóes de analfabetos pelo Brasil. Todavia, esses planos foram interrompidos pelas forças conservadoras do Golpe Militar (1964), que se julgavam ameaçadas pelo caráter revolucionário das proposiçóes de Freire e, por isso, ele foi acusado por subversão à ordem estabelecida, sendo preso e, em seguida, exilado (Gadotti, 1996; Nosella, 2007).

Nos anos de exílio, em meio a um processo doloroso diante das implicaçóes do que significava ficar distante e apartado dos seus e do seu país, Freire amplia sua luta pela libertação dos oprimidos e por justiça social, passando a compreendê-la para além dos limites nacionais, de modo que suas formulações foram assumindo nesse processo dimensões globais. Isto e o exílio o levaram a viver e realizar trabalhos no Chile, Estados Unidos da América, Suíça, Guiné-Bissau e em outros países, difundindo, debatendo, elaborando e compartilhando suas ideias e intencionalidades (Gadotti, 1996). "Se, nos anos 1960, a mensagem de Freire, lançada na região nordestina, havia se dilatado nacionalmente para todo o Brasil, na década de 1970, seu nome e seu método pedagógico expandiram-se pelo mundo" (Nosella, 2007, p. 180).

Gadotti (1996) divide a experiência e as elaboraçóes de Freire em duas fases: uma fase latino-americana, de 1960/1970, do autor de Pedagogia do Oprimido (escrito em 1968); e uma segunda fase, que denomina como Paulo Freire cidadão do mundo, de 1980/1990, com livros em diálogo e experiências pelo mundo.

Paulo Freire retorna ao Brasil definitivamente em 1980, quando deu continuidade ao desenvolvimento da sua obra, de maneira sempre engajada com os valores que propagou, contribuindo para a renovação contínua do pensamento pedagógico nacional e universal. Freire faleceu em 2 de maio de 1997, em São Paulo - Brasil, deixando um legado de proposiçóes e de luta para a busca de um mundo mais justo (Nosella, 2007).

Esse legado e a influência de Paulo Freire ainda se difundem, tendo alcançado e se espraiado por distintas áreas de conhecimento (Gadotti, 1996), inclusive na terapia ocupacional (Toldrá, 1986; Barros, 2004; Magalhães, 2012; Gontijo \& Santiago, 2018, 2020; Farias \& Lopes, 2020).

Gontijo \& Santiago (2018), em um levantamento da produção científica brasileira que articulasse terapia ocupacional e a pedagogia de Paulo Freire, identificaram trabalhos entre 2000 e 2016, com um aumento progressivo de citaçóes. As autoras concluem que as referências a esse autor resultariam da busca por bases mais críticas para compreender a própria profissão, os processos de formação profissional, bem como as intervençóes terapêutico-ocupacionais em diversos campos de práticas, pontuando, todavia, o destaque disso na subárea da terapia ocupacional social.

O exame desta presença mostrou diferentes níveis de apreensão da obra freireana, caracterizando um processo dinâmico de aproximação, que se contextualiza em meio a historicidade na qual a terapia ocupacional reflete sobre si mesma, sua relação com os e as participantes das intervençôes e seu papel de intervenção no e com o mundo (Gontijo \& Santiago, 2018, p. 145).

Farias \& Lopes (2020), ao refletirem sobre o uso do referencial freireano na terapia ocupacional, e especialmente na terapia ocupacional social, discorrem sobre as bases para pensar/fazer uma a ação profissional pautada pela educação como prática da liberdade, tendo 
como pontos chaves o compromisso ético-politico; a criticidade-problematização; a democratização; e a rigorosidade técnico-científica.

Esses autores se voltam para possíveis caminhos que interessam aos profissionais da área a partir do legado de Paulo Freire, tanto em âmbito prático como teórico, operacionalizando formulaçóes freireanas para denunciar as desigualdades e anunciar um mundo mais justo, com dialogia, liberdade, conscientização e transposição de situaçóeslimites. Proposiçóes estas que vão ao encontro de ideias já desenvolvidas por Barros (2004), trazendo a centralidade de Paulo Freire para se lançar mão de categorias como conscientização e diálogo, bem como para compreender a indissociabilidade entre ação técnica e política na profissão e a própria ideia de ação transformadora da realidade.

Assim, referenciais e aportes ${ }^{2}$ elaborados por Paulo Freire vêm sendo utilizados para informar diversas áreas de conhecimento que convergem na luta contra a opressão e na busca de alternativas às contradiçóes sociais que interpelam a vida cotidiana de sujeitos marcados por relaçôes de dominação e exploração; entre elas, está a terapia ocupacional.

Nosso intuito foi ampliar o escopo e adensar o caráter dessa presença acadêmica na terapia ocupacional, tomando como referência, para tanto, bases de dados internacionais, o que nos levou a este trabalho de revisão.

\section{Método}

Foi realizada uma revisão de escopo, metodologia apropriada para o levantamento e mapeamento da produção acadêmica de uma determinada área de conhecimento (Arksey \& O’Malley, 2005) - no caso, a terapia ocupacional em sua correlação com os aportes da obra de Paulo Freire. De forma complementar foi utilizado o The Preferred Reporting Items for Systematic Reviews and Meta-Analyses (PRISMA) extension for scoping reviews (PRISMA$S c R$ ) (Moher et al., 2009; Tricco et al., 2018).

\section{Identificando a questáo de pesquisa}

A questão de pesquisa que conduziu a revisão foi: como o referencial de Paulo Freire vem sendo utilizado em produçóes da terapia ocupacional indexadas em bases internacionais?

\section{Identificando estudos relevantes}

Inicialmente, entre março e abril de 2020, procedeu-se ao levantamento das produçóes publicadas e reunidas em três bases de dados acadêmicas, a saber: CINAHL, Scopus e Web of Science. Essas bases indexam a maioria dos periódicos científicos da área de terapia ocupacional. Os descritores utilizados como ferramentas de busca foram: "occupational

\footnotetext{
${ }^{2}$ Freire (2001a, 2013) reconhece suas elaboraçōes como uma compreensão dialética-ética-crítica-politica sobre a educação. Aqui, entende-se essa compreensão como um conjunto de referenciais teóricos e aportes metodológicos, dentro da dialética entre a reflexãoação, que diz de uma maneira de apreender a realidade (o mundo, os seres humanos e as relaçóes de poder), mas também de formas de fazer e atuar sobre essa realidade (as açóes concretas para se movimentar frente às problemáticas). Ademais, esses referenciais e aportes anunciam o que denominamos como categorias (Minayo, 2001), a exemplo de diálogo, conscientização, consciência política, práxis e outras, que articulam conceitos caracterizados por determinados princípios de Freire.
} 
therap ${ }^{*}$ ", no campo de titulo, resumo e palavras-chave ${ }^{3}$ e, "Paulo Freire", "Freire, P." $e$ "Freire, Paulo" ${ }^{4}$ no campo texto completo.

\section{Seleçáo dos estudos}

No levantamento, não foram estipulados parâmetros de ano ou idioma, tendo sido incluídos todos os artigos que referenciavam pelo menos uma obra de Paulo Freire.

\section{Mapeando os dados}

Conforme proposto por Levac et al. (2010), foi desenvolvida uma planilha no programa Microsoft Excel ${ }^{\oplus}$ para mapeamento dos dados dos artigos, a saber: título, resumo, palavras-chave, idioma, periódico, ano de publicação, tipo de artigo, autores, filiação institucional e país dos autores, obras de Paulo Freire referenciadas e número de citaçóes das mesmas ao longo do artigo.

\section{Agrupando, sintetizando e apresentando resultados}

Com a leitura inicial dos artigos reunidos incluídos, primeiramente, foi feita uma análise numérica da extensão e natureza dos estudos, utilizando-se porcentagens, tabelas e gráficos com informaçôes como: número de publicaçôes ao longo do tempo, periódicos mais presentes, ocorrência de autores e países de filiação institucional, tipos de estudos, textos de Paulo Freire mais citados e número de citaçóes no corpo do artigo e categorias de Freire mais utilizadas.

Com a leitura integral e detida, posteriormente, foram elaboradas sínteses dos conteúdos tratados nos artigos, o que fez emergir alguns eixos de análise, possibilitando um agrupamento temático dos artigos em três conjuntos: Paulo Freire como referencial para o pensar/fazer terapia ocupacional; Paulo Freire como referencial para auxiliar a pesquisa em terapia ocupacional; e Paulo Freire na formação de terapeutas ocupacionais.

\section{Análise dos dados}

As sínteses elaboradas foram tratadas por meio de um conjunto de técnicas aplicadas a conteúdos que transportam significações, de natureza linguística, icônica e outros códigos semióticos, tecendo sua relação com as estruturas sociológicas, processo que Bardin (1977) denominou como análise de conteúdo. Assim, foi aplicado nas fontes reunidas o exercício de compreender, inferir ou especular, buscando-se superar uma leitura superficial, para "[...] compreender as mensagens para além dos seus significados imediatos” (Bardin, 1977, p. 29).

\footnotetext{
${ }^{3} \mathrm{~A}$ base de dados CINAHL não possui a opção título, resumo e palavras-chave juntas e não possui o campo palavra-chave. Assim, foi realizada a pesquisa em cada uma dessas categorias separadamente: primeiro, título; depois, resumo; e, por fim, assunto (no lugar de palavra-chave).

${ }^{4}$ Os descritores "Freire, P." e "Freire, Paulo" foram incluídos, tendo em vista que essas são as grafias que aparecem nas referências dos trabalhos.
} 


\section{Resultados}

As estratégias de busca permitiram levantar 198 produções. Após a remoção da repetição daquelas que estavam em mais de uma base, de livros, capítulos de livro e editoriais, mantendo-se o foco no levantamento de textos no formato de artigos acadêmicos, foram reunidos 93 artigos. Em seguida, foram revisados referências bibliográficas e resumos, tendo sido excluídos textos que não tinham em suas referências obras de Paulo Freire (muitos referenciavam outros autores com o mesmo sobrenome) e aqueles que não apresentavam em seus resumos um foco na terapia ocupacional, como artigos que traziam temas em torno de práticas integrativas, educação em saúde, entre outros, resultando na permanência de 56 artigos. $\mathrm{Na}$ etapa seguinte, passou-se ao processo de leitura na íntegra desses 56 artigos, todos eles incluídos nesta revisão. Uma síntese desse percurso é apresentada na Figura 1.

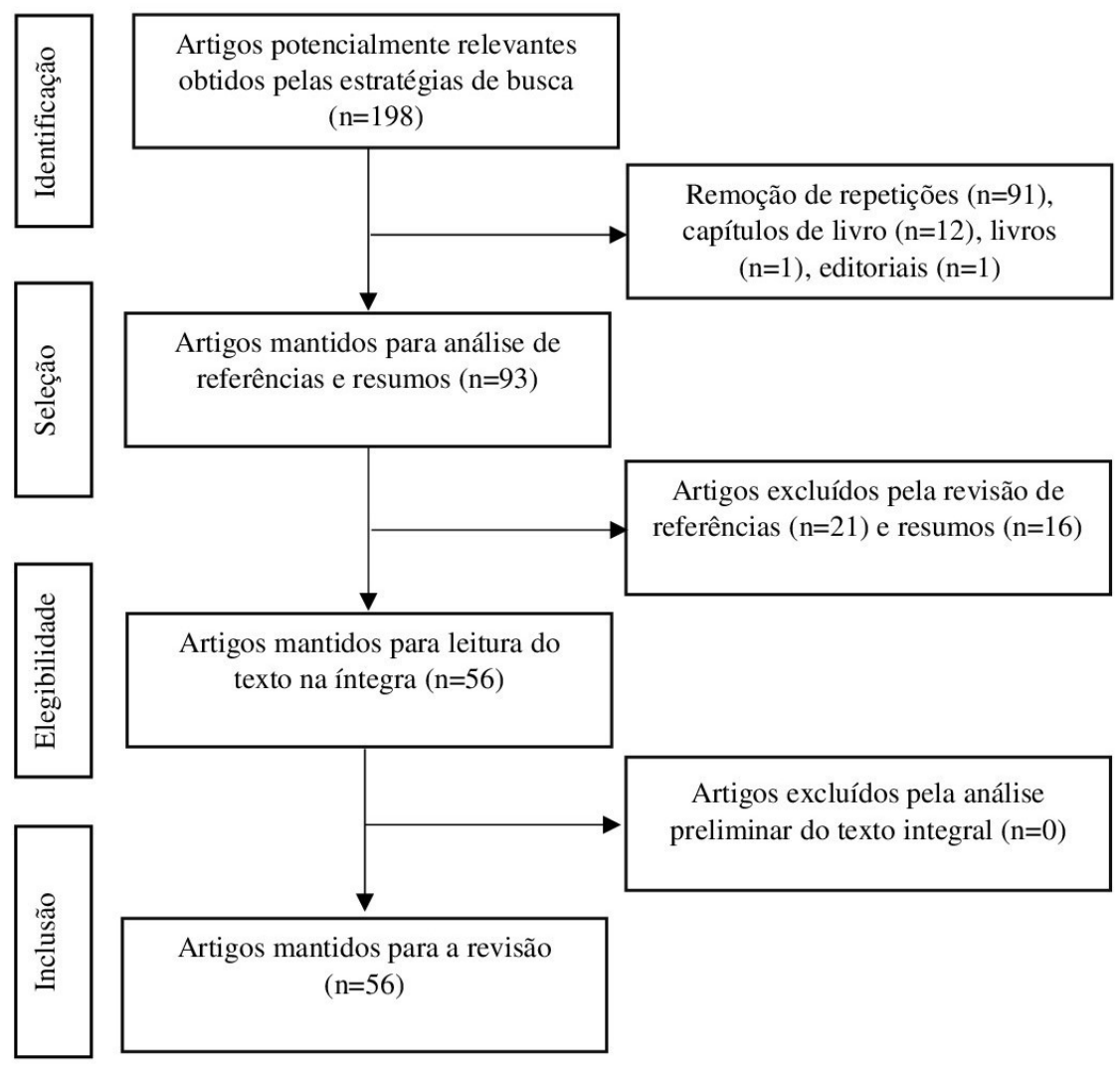

Figura 1. Fluxograma do processo de seleção usando o modelo Preferred Reporting Items for Systematic Reviews and Meta-Analyses (PRISMA) extension for scoping reviews (PRISMA-ScR) (Moher et al., 2009;

Tricco et al., 2018).

\section{Panorama da literatura reunida}

O primeiro artigo identificado que explicita a utilização do referencial de Paulo Freire é de 1993, intitulado Occupational therapy guidelines for client-centred practice: impact study 
findings, escrito por Jenny Blain e Elisabeth Townsend e publicado no Canadian Journal of Occupational Therapy. As autoras citam Freire uma vez, integrando um conjunto de autores, ao mencionarem açấo social.

De 1993 a 2017, conforme demonstra a Figura 2, as produçóes oscilaram entre zero e quatro publicaçóes, havendo um acréscimo significativo nos anos de 2018 (8) e 2019 (7). Cabe destacar que o ano de 2020 está subnotificado, já que a busca foi até abril desse ano.

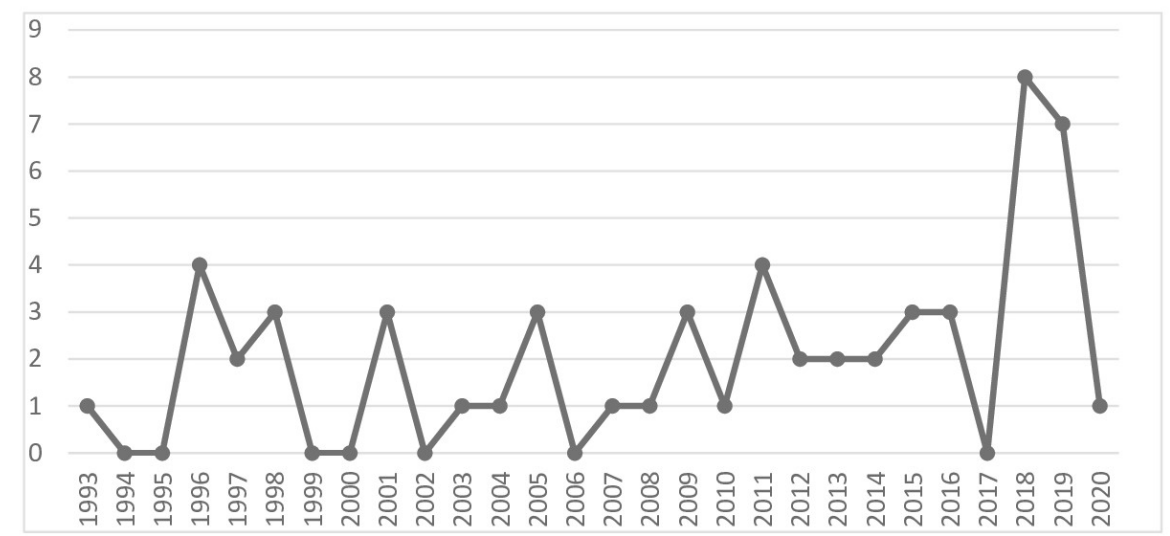

Figura 2. Número de publicaçóes por ano (1993-2020). Fonte: CINAHL, Scopus e Web of Science (Abril de 2020).

O Canadian Journal of Occupational Therapy publicou o maior número de artigos $(\mathrm{n}=10)$, seguido pelo Cadernos Brasileiros de Terapia Ocupacional $(\mathrm{n}=6)$ e pelo Occupational Therapy in Health Care $(\mathrm{n}=6)$. Ademais, vale destacar que 11 artigos foram trazidos por periódicos com uma única publicação. Isso pode ser visto com mais detalhe na Tabela 1.

Tabela 1. Distribuição de artigos publicados entre 1993 e abril de 2020, por periódico.

\begin{tabular}{ccc}
\hline Periódico & Número de artigos & $\mathbf{\%}$ \\
\hline Canadian Journal of Occupational Therapy & 10 & $17,8 \%$ \\
\hline Cadernos Brasileiros de Terapia Ocupacional & 6 & $10,7 \%$ \\
\hline Occupational Therapy in Health Care & 6 & $10,7 \%$ \\
\hline American Journal of Occupational Therapy & 4 & $7,1 \%$ \\
\hline Australian Occupational Therapy Journal & 4 & $7,1 \%$ \\
\hline British Journal of Occupational Therapy & 4 & $7,1 \%$ \\
\hline Journal of Occupational Science & 3 & $5,3 \%$ \\
\hline Occupational Therapy International & 3 & $5,3 \%$ \\
\hline Scandinavian Journal of Occupational Therapy & 3 & $5,3 \%$ \\
\hline Interface: Comunicação, Saúde, Educação & 2 & $3,5 \%$ \\
\hline Outros & 11 & $19,6 \%$ \\
\hline Total & 56 & $100 \%$ \\
\hline
\end{tabular}

Nota. Fonte: CINAHL, Scopus e Web of Science (Abril de 2020).

De 109 autores encontrados, a maioria $(\mathrm{n}=90,82,6 \%)$ publicou somente um artigo no recorte da presente revisão e 19 autores $(17,4 \%)$ publicaram dois ou mais estudos, com destaque para Elizabeth Townsend (Canadá) com nove artigos publicados, cinco deles entre 
1996 e 1998, seguida por Roseli Esquerdo Lopes (Brasil), com cinco, e Patrícia Leme de Oliveira Borba (Brasil) e Nick Pollard (Reino Unido), ambos com quatro publicaçóes.

Como trazido na Tabela 2, no que se refere à filiaçáo institucional dos 109 autores, a maioria se concentra na América (74,3\%), em quatro países diferentes, a saber: Brasil, com $37,6 \%$ dos autores em instituiçóes nesse país, seguido pelo Estados Unidos da América $(19,2 \%)$ e Canadá $(15,6 \%)$. A Oceania $(7,3 \%)$ e África $(0,9 \%)$ apresentaram os menores percentuais nesse âmbito, sendo que a Ásia não teve nenhuma menção.

Tabela 2. Continentes e países de filiação institucional dos autores.

\begin{tabular}{|c|c|c|c|c|c|}
\hline Continente & $\mathbf{n}$ & $\%$ & País & $\mathbf{n}$ & $\%$ \\
\hline \multirow{4}{*}{ América } & \multirow{4}{*}{81} & \multirow{4}{*}{$74,3 \%$} & Brasil & 41 & $37,6 \%$ \\
\hline & & & Estados Unidos da América & 21 & $19,2 \%$ \\
\hline & & & Canadá & 17 & $15,6 \%$ \\
\hline & & & Colômbia & 2 & $1,8 \%$ \\
\hline \multirow{9}{*}{ Europa } & \multirow{9}{*}{19} & \multirow{9}{*}{$17,4 \%$} & Reino Unido & 10 & $9,1 \%$ \\
\hline & & & Espanha & 2 & $1,8 \%$ \\
\hline & & & Suécia & 1 & $0,9 \%$ \\
\hline & & & Irlanda & 1 & $0,9 \%$ \\
\hline & & & Malta & 1 & $0,9 \%$ \\
\hline & & & Alemanha & 1 & $0,9 \%$ \\
\hline & & & Estônia & 1 & $0,9 \%$ \\
\hline & & & Países Baixos & 1 & $0,9 \%$ \\
\hline & & & Geórgia & 1 & $0,9 \%$ \\
\hline Oceania & 8 & $7,3 \%$ & Austrália & 8 & $7,3 \%$ \\
\hline África & 1 & $0,9 \%$ & Tunísia & 1 & $0,9 \%$ \\
\hline
\end{tabular}

Nota. Fonte: CINAHL, Scopus e Web of Science (Abril de 2020).

Dada a presença majoritária de periódicos de países anglófonos, identificou-se que 83,9\% (47) dos artigos estão apenas em língua inglesa, 8,9\% (5) em língua portuguesa, $7,1 \%$ (3) trazem versóes em português e inglês e apenas 1,7\% (1) em espanhol e inglês.

Os tipos de estudos foram classificados em artigos de pesquisa, ensaios (que trazem reflexões sobre diversas temáticas) e relatos de experiência. Em maior número, estão os artigos de pesquisa (25-44,6\%), demonstrando uma forte produção da terapia ocupacional no âmbito da investigação que utiliza o referencial de Paulo Freire, seguida por um número significativo de ensaios (20-35,7\%) e um menor número de relatos de experiências (11-19,6\%).

Sáo referenciadas 14 diferentes obras de Paulo Freire, como se pode verificar na Tabela 3, que aparecem em 72 citaçóes. O livro mais presente é Pedagogia do Oprimido (Freire, 2016), citado 37 vezes (33 em inglês e quatro em português), representando mais da metade $(51,3 \%)$ do aporte freireano referenciado em artigos publicados no universo da terapia ocupacional. 
Tabela 3. Distribuição das obras de Paulo Freire por número de citações e idioma dos artigos revisados.

\begin{tabular}{|c|c|c|c|c|}
\hline Título da obra* & Tipo & No de citaçóes & Idioma & $\%$ \\
\hline Pedagogia do oprimido & Livro & 37 & $\begin{array}{l}\text { 33inglês; } \\
4 \text { português }\end{array}$ & $51,3 \%$ \\
\hline The politics of education & Livro & 9 & inglês & $12,5 \%$ \\
\hline Educação como prática da liberdade & Livro & 5 & $\begin{array}{l}4 \text { inglês; } \\
1 \text { português }\end{array}$ & $6,9 \%$ \\
\hline Pedagogia da autonomia & Livro & 4 & português & $5,5 \%$ \\
\hline Ação cultural para a liberdade & Livro & 3 & $\begin{array}{l}1 \text { inglês; } \\
2 \text { português }\end{array}$ & $4,1 \%$ \\
\hline Education for critical consciousness & Livro & 3 & inglês & $4,1 \%$ \\
\hline Educação e mudança & Livro & 2 & português & $2,7 \%$ \\
\hline Extensão ou comunicação & Livro & 2 & $\begin{array}{l}1 \text { inglês; } \\
1 \text { português }\end{array}$ & $2,7 \%$ \\
\hline Professora sim, tia não & Livro & 2 & português & $2,7 \%$ \\
\hline Pedagogia da esperança & Livro & 1 & inglês & $1,3 \%$ \\
\hline Educadores de rua & Livro & 1 & português & $1,3 \%$ \\
\hline We can reinvent the world & Capítulo & 1 & inglês & $1,3 \%$ \\
\hline We make the road by walking & Livro & 1 & inglês & $1,3 \%$ \\
\hline What is the "dialogical method" of teaching? & Artigo & 1 & inglês & $1,3 \%$ \\
\hline Total & & 72 & & $100 \%$ \\
\hline
\end{tabular}

Nota. Fonte: CINAHL, Scopus e Web of Science (Abril de 2020). *Nas obras que só existem na versão em inglês, foram conservados os títulos originais.

Dos 56 artigos analisados, cabe destacar que 83,9\% (47) referenciam uma única obra de Paulo Freire, sendo que, em 51,7\% (29), essa única obra é Pedagogia do Oprimido, ou seja, pode-se afirmar que essa é a obra central que apoia reflexóes e análises dos autores no escopo da terapia ocupacional.

O uso de uma obra de modo isolado é refletido também no número de citaçôes ${ }^{5}$ de Paulo Freire ao longo dos artigos; a maioria, 34 (60,7\%), faz apenas uma citaçáo no texto da obra utilizada.

Em torno das obras de Freire, foram identificadas as categorias mais presentes nos artigos analisados. No total, foram elencadas 33 categorias freireanas presentes, sendo que, destas, as mais usadas foram Diálogo/Dialógica, que aparece 16 vezes, seguida por Conscientização/Consciência críticalpolítica, com 14 apariçóes, e Práxis/Ação + Reflexão, Transformação/Mudança social e Pesquisa participante/Pesquisa-Ação, todas com nove.

\section{Usos de Paulo Freire}

Tomando-se os referenciais teóricos e os aportes-metodológicos de Freire utilizados nos artigos analisados, os mesmos foram agrupados em três conjuntos: $33(58,9 \%)$ utilizam Paulo Freire como referencial para o pensar/fazer da terapia ocupacional; $10(17,8 \%)$ como

${ }^{5}$ Essa análise foi realizada tomando-se os parâmetros para citação, por exemplo, Freire (ano) ou (FREIRE, ano). 
referencial para auxiliar a pesquisa em terapia ocupacional; e 13 (23,2\%) para análises e proposiçôes que envolvem a formação de terapeutas ocupacionais.

\section{a) Paulo Freire como Referencial para o Pensar/Fazer Terapia Ocupacional}

Neste conjunto, foram reunidos os artigos que utilizam o referencial freireano para propor e discutir aspectos envolvidos em um pensar/fazer que procura informar a prática terapêutico-ocupacional. A maioria dos artigos, 33 (58,9\%), pertence a este conjunto ${ }^{6}$.

São trazidos aportes para a prática profissional junto a diversas populaçóes, como, a título de exemplo, os estudos de Blain \& Townsend (1993), Townsend (1996a; 1996b; 1997a; 1997b) e Townsend et al. (2003), que problematizam o envolvimento limitado dos profissionais no que configuraria o empoderamento dos sujeitos assistidos, devido a entraves estruturais institucionais e de práticas psico-biomédicas e individualizadas predominantes nos serviços do setor da saúde. Ao mesmo tempo, discorrem sobre a potência de práticas terapêutico-ocupacionais para açôes que rompam com essas lógicas limitadoras, tendo como finalidade a denúncia de tais questóes, por meio de uma linguagem de possibilidade e esperança que se volte para as mudanças.

As autoras, apoiadas em Paulo Freire, pontuam que o trabalho profissional para o empoderamento dos sujeitos é fundamental para uma sociedade mais justa, a ser realizado através de atividades direcionadas para conscientização e educação libertadora, ressaltando o potencial da ocupação para a transformação pessoal e social, bem como a responsabilidade profissional com relação ao agir em prol dessas questóes, tomando-se açôes mais horizontais e inclusivas com os sujeitos que atuam em conjunto. Para tanto, são necessários parâmetros que repensem a linguagem profissional (Magalhães \& Galheigo, 2010; Townsend, 1998; Phelan, 2011) e suas bases epistêmicas a partir da práxis, ou seja, a prática em dialética com a reflexão, o pensar/fazer; só assim seria possível desenvolver estratégias comprometidas com a mudança social e que não reproduzam processos de discriminação e exclusão (Kinsella \& Whiteford, 2009).

Nesse sentido, Freire aparece fortemente como um teórico crítico para elaboraçóes práticas e reflexivas que se voltam para a transformação, mudança ou justiça social no mundo (Shaw et al., 2009; McCorquodale \& Kinsella, 2015; Pollard, 2018; Malfitano et al., 2014). Townsend (2012) e Rudman (2018), ao defenderem uma perspectiva crítica na profissão, colocam a importância dela em confrontar as estruturas sociais de poder, passando a reconhecer o terapeuta ocupacional como um agente que realiza um trabalho técnico, vinculado a questóes éticas e políticas, devendo ter sensibilidade cultural e consciência política, para náo correr o risco de reduzir problemas sociais a aspectos puramente técnicos (Galheigo, 2011; Godoy-Vieira et al., 2018; Quiroga \& Reyes, 2019).

Há o reconhecimento de conexóes possíveis e potentes entre a terapia ocupacional e as perspectivas freireanas de educação, ressaltando que essas podem fomentar um pensamento crítico que auxilia o trabalho profissional junto a grupos que vivenciam a exclusão e opressão, seja por aspectos socioeconômicos, físicos ou mentais etc., sobretudo, em serviços de caráter comunitário e territorial, extra-clínico, que exigem uma prática que aja de forma

${ }^{6}$ Blain \& Townsend (1993); Frank (1996); Townsend (1996a, 1996b, 1997a, 1997b, 1998); VanLeit, (1998); Neufeld \& Kniepmann, (2001); Padilla, (2002); Townsend et al. (2003); Shaw et al. (2009); Kinsella \& Whiteford, (2009); Magalhães \& Galheigo, (2010); Lopes et al. (2011a, 2011b); Phelan, (2011); Galheigo, (2011); Townsend, (2012); Lopes et al. (2013); McCorquodale \& Kinsella, (2015); Fransen et al. (2015); Maia et al. (2016); Gontijo et al. (2016); Godoy-Vieira et al. (2018); Rudman (2018); Pollard, (2018); Silva et al. (2018); Serpa et al. (2018); Arblaster et al. (2019); Boland \& Cunningham (2018); Quiroga \& Reyes, (2019); Malfitano et al. (2014). 
mais alargada sobre as realidades dos sujeitos, para uma emancipação social (VanLeit, 1998; Frank, 1996; Padilla, 2002; Neufeld \& Kniepmann, 2001; Lopes et al., 2011a, 2011b; Fransen et al., 2015; Maia et al., 2016; Gontijo et al., 2016; Boland \& Cunningham, 2018). Isso pode ser exemplificado com a finalidade do trabalho desenvolvido com os jovens em vulnerabilidade social no Brasil, em uma Escola Pública e um Centro da Juventude, descritos por Lopes et al. (2013, p. 939), que colocam que “[...] é necessário buscar recursos que ampliem as redes sociais de suporte a esses jovens, criando espaços de pertencimento e possibilidades de tomada de consciência crítica”.

A abordagem dialógica é reiterada muitas vezes nos estudos como eixo estruturador da intervenção, que propicia a participação ativa dos sujeitos, a construção de vínculo e a valorização das experiências cotidianas vividas (Arblaster et al., 2019; Silva et al., 2018; Serpa et al., 2018).

b) Paulo Freire com Referencial para Auxiliar a Pesquisa em Terapia Ocupacional

Dez $(17,8 \%)$ artigos $^{7}$ utilizam o referencial freireano para subsidiar alternativas de pesquisa em terapia ocupacional.

Wright (1998), ao propor caminhos de pesquisa para terapeutas ocupacionais, apoia-se em Freire para discutir a pesquisa-ação, caracterizada como uma pesquisa participante, frisando o envolvimento dos participantes na produçáo de diálogos para a consciência crítica. Nessas bases, configura-se o que se denomina como Pesquisa Ação Participante (Participatory Action Research - PAR) (Taylor et al., 2004; Wilding \& Whiteford, 2007), também como auxílio para o desenvolvimento de práticas terapêutico-ocupacionais, já que possibilitaria uma apreensão ampla das demandas e necessidades de sujeitos que se tornariam ativos nos processos. Dessa forma, a pesquisa participante junto a pessoas e grupos sociais tradicionalmente oprimidos se apoia nas categorias de diálogo, conscientização e empoderamento, propondo o desenvolvimento de estratégias de reflexão mútua entre sujeitos pesquisados e pesquisadores, a fim de uma açáo conjunta para que os sujeitos se capacitem para melhorar suas condiçôes de vida, enfrentando as estruturas de opressão.

A pesquisa participante seria uma forma de atuação conjunta em favor da cooperação, emancipação e justiça social, indo além da "simples" coleta de dados (Wilding \& Whiteford, 2008). Buscaria superar modelos positivistas de ciência, pautando-se por uma abordagem igualitária e comprometida entre pesquisador/terapeuta ocupacional e participante, em que ambos se apropriam dos conhecimentos produzidos (Blakeney \& Marshall, 2009; Zubriski et al., 2020), afirmando-se determinado papel social da pesquisa (Bryant et al., 2019). Aparecem ainda outras estratégias de pesquisa mencionadas nos artigos, como a etnografia (Pastore \& Sato, 2018), que se baseariam em processos relacionais e dialógicos potentes para uma pesquisa que abarque diferentes modos de vida, problemáticas e questóes que perpassam as sociedades. O diálogo é colocado também como um método para a pesquisa, entendendo que esse produz discursos sociopolíticos que geram reflexão, conscientização e transformações (Farias \& Rudman, 2019; Farias et al., 2019).

c) Paulo Freire na e para a Formaçáo de Terapeutas Ocupacionais

${ }^{7}$ Wright (1998); Taylor et al. (2004); Wilding \& Whiteford (2007, 2008); Blakeney \& Marshall (2009); Pastore \& Sato (2018); Farias \& Rudman (2019); Bryant et al. (2019); Farias et al. (2019); Zubriski et al. (2020). 
Os $13(23,2 \%)$ artigos aqui agrupados ${ }^{8}$ são aqueles que mencionavam Paulo Freire para fazer análises e proposiçôes no contexto da formação profissional de terapeutas ocupacionais, fosse ela inicial ou continuada.

Problematizando a divisão entre teoria e prática, Steward (1996) pontua a importância da relação entre essas duas dimensóes na formação de estudantes de terapia ocupacional, destacando, a partir de Freire, a necessidade de uma abordagem prática reflexiva, que valorize a experiência desses sujeitos no processo educativo, pautada, então, pela ação + reflexão. O pressuposto é que essa práxis iria ao encontro da superação de processos decorrentes de uma educação bancária, formulaçáo de Freire (2016) em torno de uma educação com educandos passivos e apenas receptores de conhecimento, colocando então os formandos como sujeitos ativos nos processos (Bonello, 2001).

Em diversos desses artigos, as elaboraçóes freireanas são aportes para discutir práticas de formação atreladas à bolsa de estudos de prática (Scholarship of Practice), que se baseia na pesquisa participante, uma proposição descrita como tendo surgido na Universidade de Illinois em Chicago (UIC), cujo objetivo era estreitar os laços entre prática, investigação e teoria, com o compromisso de estudos que respondessem às práticas junto às demandas de diversos públicos, sendo também um espaço de formação de terapeutas ocupacionais. Novamente, a presença da pesquisa participante, de sujeitos (no caso, profissionais) que se formariam a partir do trabalho concreto que maximiza o envolvimento, bem como do diálogo como fundamento para lidar com demandas individuais e comunitárias, consolidando estratégias para uma consciência crítica (Kielhofner, 2005; Suarez-Balcazar et al., 2005a, 2005b, 2015). O envolvimento é um elemento importante nas discussóes, entendendo-se que o terapeuta ocupacional em formação necessita da experimentação de si, do mundo e do estar com o outro, como pontuam Borba et al. (2018), a partir de Freire.

Nesses termos, as reflexôes se direcionam para a construção de um compromisso social do terapeuta ocupacional em formação, para que esses não realizem a manutenção do status quo ou reforcem estereótipos de populações em vulnerabilidade, voltando suas açóes para a mudança social, sobretudo, no trabalho comunitário, que não deve ser confundido como trabalho de benemerência ou caridade (Hansen, 2013).

Reafirma-se também aqui o diálogo como um eixo importante em toda trajetória de formação dos profissionais, enquanto proposta pedagógica que oriente os currículos (Barba et al., 2012), tendo em vista a necessidade de instituiçóes de ensino superior contribuírem para o capital social e preparo de profissionais para serem membros ativos das comunidades em que vivem (McGrath et al., 2014). Sendo capacitados para compreender histórias pessoais localizadas na complexidade das contradiçóes mais amplas e, assim, agir sobre elas (Walsh, 2016), ressaltando-se a necessidade da incorporação de conhecimento e pedagogias críticas ao processo formativo nos diferentes níveis de educação em terapia ocupacional (Malfitano et al., 2018; Walsh \& Pollard, 2019).

\section{Discussáo}

Primeiramente, é necessário destacar a centralidade de Pedagogia do Oprimido como obra importante no campo. Beisiegel (2016), ao escrever o prefácio da $60^{\circ}$ ediçáo desse livro, pela editora brasileira Paz \& Terra, ressalta o seu lugar como uma das obras com mais

${ }^{8}$ Steward (1996); Bonello (2001); Kielhofner (2005); Suarez-Balcazar et al. (2005a, 2005b); Barba et al. (2012); Hansen (2013); McGrath et al. (2014); Suarez-Balcazar et al. (2015); Walsh (2016); Malfitano et al. (2018); Borba et al. (2018); Walsh \& Pollard (2019). 
destaque na produção do autor. Ela foi concluída durante seu exílio, no Chile, em 1968 (ano do seu manuscrito em língua portuguesa), sendo que sua primeira publicação foi em língua inglesa em 1970; até 1974, havia sido traduzida para o espanhol, italiano, alemão, holandês e sueco. Santana \& Souza (2019), em uma análise bibliométrica entre os anos 1968-2017 (50 anos da sua primeira versão), identificaram que esse livro é encontrado em 57 idiomas, em 200 ediçóes e com mais de mil citaçóes por ano em publicaçóes acadêmicas, demonstrando sua difusão e apropriação mundial. Ademais, o movimento de internacionalização dessa obra, que inclusive foi identificado aqui, é explicado por sua primeira publicaçáo em inglês e por toda a trajetória que o autor construiu na condiçáo de intelectual e exilado político em diversos países.

O lugar central da Pedagogia do Oprimido fica evidente também pelo fato de, em mais da metade dos artigos (37), ser a única obra citada, inclusive, quando em uma única vez.

Por outro lado, esses fatos demonstram os limites em relação ao uso das obras de Paulo Freire, ficando notório que, em muitos artigos, isso leva a uma apropriaçáo superficial do referencial freireano, na medida em que não se trabalha com elaboraçôes que esse autor amadurece ao longo de sua vasta produçáo.

Somado a isso, as citaçóes de Freire, por vezes, vêm junto com outros autores, náo deixando elucidado como o referencial do autor é pensado na elaboração em questão, a exemplo, em trechos que discorrem sobre transformação social, ação social, consciência crítica, poder, esperança etc. Não é exposta a interpretação que se fez de Freire para trabalhar com essas categorias, o que nos parece uma utilização mais pontual/isolada para resolver um aspecto teórico.

A leitura de Freire que se restringe a uma única obra, ou qualquer apreensão limitada das obras/categorias, é um aspecto duramente criticado pelo próprio autor, que denomina esses leitores como turistas freireanos (Freire, 2001b).

Resumindo, muitos educadores (as) que me utilizam de modo superficial como um meio para resolver seus problemas técnicos pedagogicamente, são, em certa medida, turistas freireanos. Eles quase se tornam fundamentalistas freireanos, e então o mundo torna-se fixo, eliminando-se a possibilidade de a histórica ser uma possibilidade (Freire, 2001b, p. 61).

Freire aponta esse aspecto como contraditório, tendo em vista que o caminho para uma práxis progressista pressupóe o adensamento de referenciais, articulados com uma (re)invenção, de acordo com as realidades e com a historicidade.

Tal limitação parece igualmente em Garzon et al. (2018), que analisaram a aplicação teórica e metodológica da pedagogia crítica libertadora de Paulo Freire na produção científica da enfermagem, concluindo que há um uso isolado/parcial de categorias freireanas nos estudos, o que representaria uma fragilidade que simplifica o referencial teórico-metodológico de Paulo Freire, indicando, assim, a necessidade de maiores investimentos da área.

Diálogo/Dialógica e Conscientização/Consciência crítica/política foram apontadas como categorias mais frequentes para informar a área da terapia ocupacional, corroborando estudos de Gontijo \& Santiago na produçáo nacional da terapia ocupacional e de Garzon et al. (2018) na enfermagem. 
Entende-se que essas formulações são centrais no livro mais utilizado, Pedagogia do Oprimido, conforme Santana \& Souza (2019), que pontuam que autores que referenciaram trechos dessa obra como elemento de discussão citam com mais frequência as palavras diálogo e conscientização, como igualmente observado nesta revisão.

Cabe destacar que essas não são categorias isoladas, como aparecem em alguns artigos, mas integram um referencial denso e amplo, em que diálogo, por exemplo, não pode ser compreendido somente como um método, mas sim como proposição teórico-metodológica que implica na assunção de uma concepção de educação, de mundo e de ser humano, aspectos fundamentais propostos por Freire em diversos livros em que foi autor e coautor.

Para Farias \& Lopes (2020, p.1350), é importante apreender as categorias freireanas sem perder a noção de que são dinâmicas e que "[...] há uma dialética em todas as suas formulaçóes, concepçóes, denúncias e anunciações (dentro de uma categoria se anuncia uma diversidade de outras)", um terreno a ser explorado em sua complexidade pelos terapeutas ocupacionais.

Essa relação dialética e complexa se dá, por exemplo, na medida em que a dialogicidade é a essência da educação como prática da liberdade, um momento de encontro entre os sujeitos para a refletir, fazer e refazer o mundo, para assim transformá-lo. Trata-se da base para os processos de conscientização, como algo que vai além do "tomar consciência", em que se busca a movimentação necessária para uma inserçáo emancipada no processe histórico, como sujeitos de decisão e compromisso, processo contínuo de práxis criadora (Freire, 2016, 2005; Shor \& Freire, 1987).

Portanto, diálogo ou conscientização, nessa elaboração, não são categorias que isoladamente dâo conta de informar a terapia ocupacional, exigindo entendimento dos princípios que estruturam tal proposta; isso se dá igualmente com outras categorias, como empoderamento, práxis, transformação etc.

É interessante perceber os destaques que envolvem a Pesquisa participante/Pesquisa-Ação, categorias inspiradas em Freire que não são, porém, elaborações diretas desse autor; são noções formuladas por outros autores, tomando-se proposiçóes freireanas sobre um modo de fazer/pensar a investigação baseada na dialogicidade da educação libertadora e conscientizadora. Ou seja, que pressupóe uma açáo de pesquisa pedagógica e em conjunto, em que investigadores e investigados "[...] são ambos sujeitos do processo" (Freire, 1987, p. 56).

Tais pressupostos vêm informando a práxis de terapeutas ocupacionais de modo interessante, dentro daquilo que parece ser potente para uma práxis que articule uma pesquisa interessada na transformação direta da realidade - com compromisso social. Mesmo que, por vezes, ocorra a já referida utilização de categorias isoladas, sem localizar inclusive que se trata de uma categoria inspirada pelo autor.

Práxis/Ação e Reflexão e Transformação/Mudança social também se sobressaem, sendo práxis uma categoria difundida por Freire para explicar a unidade dialética entre ação e reflexão. "A práxis, porém, é reflexão e ação dos homens [e mulheres] sobre o mundo para transformá-lo, sem ela, é impossível a superação da contradição opressor-oprimidos" (Freire, 1987, p. 21); assim, é o eixo central para os processos de transformação social, para uma radicalização libertadora. Esse sobressair diz de um exercício importante de terapeutas ocupacionais em pensarem a açáo de mudança concreta, sem perder de vista a dimensão reflexiva.

A transformação/mudança social é uma categoria importante, do nosso ponto de vista, que aparece nos artigos, caracterizando a busca de uma perspectiva mais crítica no âmbito da terapia ocupacional. Em Freire (1987, 2001b), a transformação social pressupóe uma realidade mais 
justa, em que os sujeitos possam ser mais, realizando-se em sua vocação para a humanização, sendo um processo de mudança perpassado por conscientização e posicionamento dos sujeitos, para se caminhar em direção à transformação social, coletiva e estrutural.

Ainda que de maneira limitada quanto a uma apropriação mais densa dos referenciais, os artigos dialogam com essa perspectiva de transformação, direcionando-se a um pensar/fazer mais crítico, que significa ser mais coletivo, social, extra-clínico, comunitário, não biomédico etc. $\mathrm{Ou}$ seja, são práticas/reflexão/ação que visam superar análises individualizadas/institucionalizadas sobre as problemáticas em questão, tecendo uma compreensão sobre os sujeitos e as estruturas de opressão que transita entre o individual e o coletivo.

É interessante perceber que a busca por essa terapia ocupacional dentro de uma perspectiva crítica e para a transformação social, mesmo demandando maiores aprofundamentos, amplia aportes para a terapia ocupacional tanto na prática direta quanto na pesquisa e na formação profissional.

Com base na leitura da terapia ocupacional social, parece-nos que há uma terapia ocupacional que, a partir dos referenciais freireanos, procuraria engendrar possibilidades para uma emancipaçáo individual e social (Barros et al., 2007). Para isso, à luz de Freire (Shor \& Freire, 1986), é necessário pensar uma intervenção que envolve o "empoderamento" individual, em que o sujeito da intervenção passa a ter uma percepção crítica e problematizadora da sociedade, reconhecendo-se como agente, e social, já que a transformaçáo social depende do poder contratual da classe social, que resulta da luta das classes oprimidas - pela obtenção de poder político no processo histórico.

Freire nos fala da necessidade do exercício de uma curiosidade metódica, central para abordagens mais críticas e radicais (Freire, 1996, 2001a), da qual precisam se valer também os terapeutas ocupacionais, para elaborarem mais sistematicamente um pensar/fazer para a transformação social, que não se estagne na reprodução simplificada, restringindo-se a um verbalismo sectário (Freire, 1987).

Foi possível reconhecer em artigos revisados contribuiçôes nesse caminho, descrevendo exercícios de sistematização com base em modelos de empoderamento, abordagens libertadoras de educação ou no aporte teórico-metodológico da Educação como Prática para Liberdade. Todavia, o acento ainda é muito mais descritivo que efetivamente propositivo/analítico.

\section{Conclusáo}

Sintetizando os resultados discutidos, na direção de responder à nossa questão de pesquisa, pontuamos que autores da área de terapia ocupacional têm utilizado o referencial de Paulo Freire para elaboraçóes que envolvem a produção de conhecimento, a formação e a prática profissional.

De modo geral, as propostas freireanos fundamentariam uma abordagem profissional crítica, intencionada para engendrar, junto a populaçóes vulneráveis, movimentos de transformação social, na dialética entre o micro e macrossocial.

Destaca-se também a necessidade de esforços para um maior aprofundamento nesse mesmo referencial, superando leituras superficiais que se restrinjam a uma única obra.

Não obstante, dentro do escopo alcançado por esta revisão, pode-se afirmar que Paulo Freire vem informando a terapia ocupacional de diversas maneiras, no fazer/pensar a intervenção juntos aos sujeitos, nos processos teórico-reflexivos e nas proposições de formação profissional. Embora, em boa parte das vezes, as categorias freireanas e o próprio 
referencial teórico-metodológico mais amplo não sejam o centro dos esforços de elaboração, o que todas essas formas de se apropriar das construçóes desse autor têm em comum é a busca por uma práxis (ação + reflexão) terapêutico-ocupacional técnica, política, crítica e que se quer comprometida com a transformação social.

Finalmente, cabe observar que este estudo traz como limitação o fato de suas reflexôes terem sido construídas a partir de artigos reunidos por meio de um levantamento em três bases de dados relevantes para o meio acadêmico, mas restritas a um universo específico. Ademais, esse recorte envolveu apenas artigos, não incluindo livros, capítulos de livros, editoriais, dentre outros produtos. Portanto, são importantes estudos que possam ampliar esse escopo, bem como pesquisas que se voltem para a apreensão do uso desse referencial na prática de profissionais que estão na assistência em diferentes serviços, ou seja, para compreender como se transformam em açôes em uma variedade de práticas de terapeutas ocupacionais.

\section{Referências}

Arblaster, K., Mackenzie, L., Gill, K., Willis, K., \& Matthews, L. (2019). Capabilities for recovery-oriented practice in mental health occupational therapy. British Journal of Occupational Therapy, 82(11), 675684. http://dx.doi.org/10.1177/0308022619866129.

Arksey, H., \& O’Malley, L. (2005). Scoping studies: towards a methodological framework. International Journal of Social Research Methodology, 8(1), 19-32. http://dx.doi.org/10.1080/1364557032000119616.

Barba, P. C. D. S. D., Silva, R. F. D., Joaquim, R. H. V. T., \& Brito, C. M. D. D. (2012). Formação inovadora em terapia ocupacional. Interface, 16(42), 829-842. http://dx.doi.org/10.1590/S141432832012000300019.

Bardin, L. (1977). Análise de conteúdo. Lisboa: Ediçōes 70.

Barros, D. D., Lopes, R. E., \& Galheigo, S. M. (2007). Novos espaços, novos sujeitos: a terapia ocupacional no trabalho territorial e comunitário. In A. Cavalcanti \& C. Galvão (Eds.), Terapia ocupacional (pp. 354-363). Rio de Janeiro: Guanabara Koogan.

Barros, D. D. (2004). Terapia ocupacional social: o caminho se faz ao caminhar. Revista de Terapia Ocupacional da Universidade de São Paulo, 15(3), 90-97. http://dx.doi.org/10.11606/issn.22386149.v15i3p90-97.

Beisiegel, C. R. (2016). Prefácio à 60ª edição. In P. Freire (Ed.), Pedagogia do oprimido (pp. 11-31). São Paulo: Paz e Terra.

Blain, J., \& Townsend, E. (1993). Occupational therapy guidelines for client-centred practice: impact study findings. Canadian Journal of Occupational Therapy, 60(5), 271-285. PMid:10130536. http://dx.doi.org/10.1177/000841749306000508.

Blakeney, A. B., \& Marshall, A. (2009). Water quality, health, and human occupations. AJOT, 63(1), 46-57. PMid:19192727.

Boland, L., \& Cunningham, M. (2018). Homelessness: critical reflections and observations from an occupational perspective. JOS, 26(2), 308-315. http://dx.doi.org/10.1080/14427591.2018.1512006.

Bonello, M. (2001). Perceptions of fieldwork education in Malta: challenges and opportunities. Occupational Therapy International, 8(1), 17-33. PMid:11823868. http://dx.doi.org/10.1002/oti.129.

Borba, P. L. O., Savani, A. C. C., Sousa, P. G. F., Medeiros, V. H. R., \& Jurdi, A. P. S. (2018). Espaços de experimentação: potência do encontro, do fazer e a ampliação do repertório de atividades. Cad. Bras. Ter. Ocup, 26(1), 219-224. http://dx.doi.org/10.4322/2526-8910.ctoRE0998.

Bryant, W., Cordingley, K., Adomako, E., \& Birken, M. (2019). Making activism a participatory, inclusive and developmental process. Disability \& Society, 34(7-8), 1264-1288.

http://dx.doi.org/10.1080/09687599.2019.1613963. 
Farias, L., \& Rudman, D. L. (2019). Challenges in enacting occupation-based social transformative practices. Canadian Journal of Occupational Therapy, 86(3), 243-252. PMid:30803264. http://dx.doi.org/10.1177/0008417419828798.

Farias, L., Rudman, D. L., Pollard, N., Schiller, S., Malfitano, A. P. S., Thomas, K., \& van Bruggen, H. (2019). Critical dialogical approach: a methodological direction for occupation-based social transformative work. Scandinavian Journal of Occupational Therapy, 26(4), 235-245. PMid:29724120. http://dx.doi.org/10.1080/11038128.2018.1469666.

Farias, M. N., \& Lopes, R. E. (2020). Terapia ocupacional social: formulaçóes à luz de referenciais freireanos. Cadernos Brasileiros de Terapia Ocupacional, 28(4), 1346-1356. http://dx.doi.org/10.4322/2526-8910.ctoEN1970.

Fiori, E. M. (1987). Prefácio. In P. Freire (Ed.), Pedagogia do oprimido (pp. 5-11). Rio de Janeiro: Paz e Terra.

Frank, G. (1996). Life histories in occupational therapy clinical practice. AJOT, 50(4), 251-264. PMid:8712245. http://dx.doi.org/10.5014/ajot.50.4.251.

Fransen, H., Pollard, N., Kantartzis, S., \& Viana-Moldes, I. (2015). Participatory citizenship: critical perspectives on client-centred occupational therapy. Scandinavian Journal of Occupational Therapy, 22(4), 260-266. PMid:25937095. http://dx.doi.org/10.3109/11038128.2015.1020338.

Freire, P. (1987). Pedagogia do oprimido. Rio de Janeiro: Paz e Terra.

Freire, P. (1996). Pedagogia da autonomia. São Paulo: Paz e Terra.

Freire, P. (2001a). Politica e educação. São Paulo: Cortez.

Freire, P. (2001b). Pedagogia dos sonhos possiveis. São Paulo: UNESP.

Freire, P. (2005). A Educaçâo na cidade. São Paulo: Cortez.

Freire, P. (2013). À sombra desta mangueira. Rio de Janeiro: Paz e Terra.

Freire, P. (2016). Pedagogia do oprimido. São Paulo: Paz e Terra.

Gadotti, M. (1996). A voz do biógrafo brasileiro: a prática à altura do sonho. In M. Gadotti (Ed.), Paulo Freire: uma biobibliografia (pp. 69-116). São Paulo: Cortez.

Galheigo, S. (2011). What needs to be done? Australian Occupational Therapy Journal, 58(2), 60-66. PMid:21418227. http://dx.doi.org/10.1111/j.1440-1630.2011.00922.x.

Garzon, A. M. M., Silva, K. L., \& Marques, R. C. (2018). Liberating critical pedagogy of Paulo Freire in the scientific production of Nursing 1990-2017. Revista Brasileira de Enfermagem, 71(4, Supl. 4), 17511758. PMid:30088649. http://dx.doi.org/10.1590/0034-7167-2017-0699.

Godoy-Vieira, A., Soares, C. B., Cordeiro, L., \& Campos, C. S. (2018). Inclusive and emancipatory approaches to occupational therapy practice in substance-use contexts. Canadian Journal of Occupational Therapy, 85(4), 307-317. PMid:30428689. http://dx.doi.org/10.1177/0008417418796868.

Gontijo, D. T., Vasconcelos, A. C. S., Monteiro, R. J. S., Facundes, V. L. D., Trajano, M. F. C., \& Lima, L. S. (2016). Occupational therapy and sexual and reproductive health promotion in adolescence. Occupational Therapy International, 23(1), 19-28. PMid:26174484. http://dx.doi.org/10.1002/oti.1399.

Gontijo, D. T., \& Santiago, M. E. (2018). Terapia ocupacional e pedagogia Paulo Freire: configurações do encontro na produção científica nacional. Reflexão e Ação, 26(1), 132-148. http://dx.doi.org/10.17058/rea.v26i1.11667.

Gontijo, D. T., \& Santiago, M. E. (2020). Autonomia e terapia ocupacional: reflexóes à luz do referencial de Paulo Freire. REVISBRATO, 4(1), 2-18. http://dx.doi.org/10.47222/2526-3544.rbto31474.

Hansen, A. M. W. (2013). Bridging theory and practice: occupational justice and service learning. Work, 45(1), 41-58. PMid:23531570. http://dx.doi.org/10.3233/WOR-131597.

Kielhofner, G. (2005). A scholarship of practice: creating discourse between theory, research and practice. Occupational Therapy in Health Care, 19(1-2), 7-16. PMid:23927698.

http://dx.doi.org/10.1080/J003v19n01_02. 
Kinsella, E. A., \& Whiteford, G. E. (2009). Knowledge generation and utilisation in occupational therapy. Australian Occupational Therapy Journal, 56(4), 249-258. PMid:20854525. http://dx.doi.org/10.1111/j.1440-1630.2007.00726.x.

Levac, D., Colquhoun, H., \& O’Brien, K. K. (2010). Scoping studies: advancing the methodology. Implementation Science, 5, 69. PMid:20854677. http://dx.doi.org/10.1186/1748-5908-5-69.

Lopes, R. E., Borba, P. L. D. O., \& Monzeli, G. A. (2013). Expressão livre de jovens por meio do Fanzine: recurso para a terapia ocupacional social. Saúde e Sociedade, 22(3), 937-948. http://dx.doi.org/10.1590/S0104-12902013000300027.

Lopes, R., Borba, P. D., \& Cappellaro, M. (2011a). Acompanhamento individual e articulação de recursos em terapia ocupacional social: compartilhando uma experiência. O Mundo da Saúde, 35(2), 233-238.

Lopes, R., Borba, P. D., Trajber, N. K., Silva, C., \& Cuel, B. T. (2011b). Oficinas de atividades com jovens da escola pública: tecnologias sociais entre educação e terapia ocupacional. Interface, 15(36), 277-288. http://dx.doi.org/10.1590/S1414-32832011000100021.

Magalhães, L. (2012). What would Paulo Freire think of occupational science? In G. E. Whiterford \& C. Hocking (Eds.), Occupational science: society, inclusion, participation (pp. 8-22). West Sussex: WileyBlackwell. http://dx.doi.org/10.1002/9781118281581.ch2.

Magalhães, L., \& Galheigo, S. M. (2010). Enabling international communication among Brazilian occupational therapists. Occupational Therapy International, 17(3), 113-124. PMid:20564687. http://dx.doi.org/10.1002/oti.292.

Maia, F. B., Teixeira, E. R., Silva, G. V., \& Gomes, M. K. (2016). The use of assistive technology to promote care of the self and social inclusion in patients with sequels of leprosy. PLoS Neglected Tropical Diseases, 10(4), e0004644. PMid:27124408. http://dx.doi.org/10.1371/journal.pntd.0004644.

Malfitano, A. P. S., Lopes, R. E., Magalhães, L., \& Townsend, E. A. (2014). ocial occupational therapy: conversations about a Brazilian experience. Canadian Journal of Occupational Therapy, 81(5), 298-307. PMid:25702374. http://dx.doi.org/10.1177/0008417414536712.

Malfitano, A. P., Monzeli, G. A., Bardi, G., \& Lopes, R. E. (2018). Scope of occupational therapy postgraduate degrees around the world. Revista de la Facultad de Medicina, 66(3), 335-341. http://dx.doi.org/10.15446/revfacmed.v66n3.63395.

McCorquodale, L., \& Kinsella, E. A. (2015). Critical reflexivity in client-centred therapeutic relationships. Scandinavian Journal of Occupational Therapy, 22(4), 311-317. PMid:25719904. http://dx.doi.org/10.3109/11038128.2015.1018319.

McGrath, M., Moldes, I. V., Fransen, H., Hofstede-Wessels, S., \& Lilienberg, K. (2014). Communityuniversity partnerships in occupational therapy education. Disability and Rehabilitation, 36(4), 344-352. PMid:23639068. http://dx.doi.org/10.3109/09638288.2013.788220.

Minayo, M. C. S. (2001). Pesquisa social: teoria, método e criatividade. Petrópolis: Vozes.

Moher, D., Liberati, A., Tetzlaff, J., \& Altman, D. G. (2009). Preferred reporting items for systematic reviews and meta-analyses: the PRISMA statement. PLoS Medicine, 6(7), e1000097. PMid:19621072. http://dx.doi.org/10.1371/journal.pmed.1000097.

Neufeld, P., \& Kniepmann, K. (2001). Gateway to wellness: An occupational therapy collaboration with the National Multiple Sclerosis Society. Occupational Therapy in Health Care, 13(3-4), 67-83. PMid:23944262. http://dx.doi.org/10.1300/j003v13n03_07.

Nosella, P. (2007). Paulo Freire: orgulho dos educadores brasileiros. EccoS, 9(1), 173-182. http://dx.doi.org/10.5585/eccos.v9i1.493.

Padilla, R. (2002). Teaching approaches and occupational therapy psychoeducation. Occupational Therapy in Mental Health, 17(3-4), 81-95. http://dx.doi.org/10.1300/J004v17n03_06.

Pastore, M. D. N., \& Sato, M. T. (2018). Pelos caminhos da diversidade sociocultural: diálogos entre terapia ocupacional, África e Etnografia. Cadernos Brasileiros de Terapia Ocupacional, 26(4), 952-959. http://dx.doi.org/10.4322/2526-8910.ctoARF1240. 
Phelan, S. (2011). Constructions of disability: a call for critical reflexivity in occupational therapy. Canadian Journal of Occupational Therapy, 78(3), 164-172. PMid:21699010. http://dx.doi.org/10.2182/cjot.2011.78.3.4.

Pollard, N. (2018). The Dr Elizabeth Casson memorial lecture 2018. British Journal of Occupational Therapy, 81(9), 487-494. http://dx.doi.org/10.1177/0308022618789583.

Quiroga, D. M. O., \& Reyes, M. S. (2019). Terapia ocupacional en comunidad. Cadernos Brasileiros de Terapia Ocupacional, 27(1), 197-207. http://dx.doi.org/10.4322/2526-8910.ctoRE1715.

Rudman, D. L. L. (2018). Occupational therapy and occupational Science. Cadernos Brasileiros de Terapia Ocupacional, 26(1), 241-249. http://dx.doi.org/10.4322/2526-8910.ctoEN1246.

Santana, O. A., \& Souza, S. C. (2019). Pedagogia do oprimido como referência: 50 anos de dados geohistóricos (1968-2017) e o perfil de seu leitor. Revista História da Educação, 23, 1-31. http://dx.doi.org/10.1590/2236-3459/83528.

Serpa, E. A., Lima, A. C. D. D., \& Silva, Â. C. D. D. (2018). Terapia ocupacional e grupo hiperdia. Cadernos Brasileiros de Terapia Ocupacional, 26(3), 680-691. http://dx.doi.org/10.4322/2526-8910.ctoRE0784.

Shaw, L., Bondy, K., \& Dodman, J. (2009). Client insights on knowledge use and access in return to work. Canadian Journal of Occupational Therapy, 76(5), 359-367. http://dx.doi.org/10.1177/000841740907600507.

Shor, I., \& Freire, P. (1986). Medo e ousadia: o cotidiano do professor. Rio de Janeiro: Paz e Terra.

Shor, I., \& Freire, P. (1987). What is the "dialogical method" of teaching? Journal of Education, 169(3), 1131. http://dx.doi.org/10.1177/002205748716900303.

Silva, C. R., Silvestrini, M. S., von Poellnitz, J. C., Prado, A. C. S. A., \& Leite Junior, J. D. (2018). Estratégias criativas e a população em situação de rua. Cadernos Brasileiros de Terapia Ocupacional, 26(2), 489-500. http://dx.doi.org/10.4322/2526-8910.ctoRE1128.

Steward, B. (1996). The theory/practice divide: bridging the gap in occupational therapy. British Journal of Occupational Therapy, 59(6), 264-268. http://dx.doi.org/10.1177/030802269605900604.

Suarez-Balcazar, Y., Hammel, J., Helfrich, C., Thomas, J., Wilson, T., \& Head-Ball, D. (2005a). A model of university-community partnerships for occupational therapy scholarship and practice. Occupational Therapy in Health Care, 19(1-2), 47-70. PMid:23927701. http://dx.doi.org/10.1080/j003v19n01_05.

Suarez-Balcazar, Y., Martinez, L. I., \& Casas-Byots, C. (2005b). A participatory action research approach for identifying health service needs of hispanic immigrants: implications for occupational therapy. Occupational Therapy in Health Care, 19(1-2), 145-163. PMid:23927707. http://dx.doi.org/10.1080/j003v19n01_11.

Suarez-Balcazar, Y., Mirza, M. P., \& Hansen, A. M. W. (2015). Unpacking university-community partnerships to advance scholarship of practice. Occupational Therapy in Health Care, 29(4), 370-382. PMid:26053328. http://dx.doi.org/10.3109/07380577.2015.1037945.

Taylor, R. R., Braveman, B., \& Hammel, J. (2004). Developing and evaluating community-based services through participatory action research. AJOT, 58(1), 73-82. PMid:14763638. http://dx.doi.org/10.5014/ajot.58.1.73.

Toldrá, R. C. (1986). Terapia ocupacional e educação popular. In P. Freire, A. Nogueira \& D. Mazza (Eds.), Fazer escola conhecendo à vida (pp. 83-88). São Paulo: Papirus.

Townsend, E. (1996a). Institutional ethnography: a method for showing how the context shapes practice. The Occupational Therapy Journal of Research, 16(3), 179-199. http://dx.doi.org/10.1177/153944929601600303.

Townsend, E. (1996b). Enabling empowerment: using simulations versus real occupations. Canadian Journal of Occupational Therapy, 63(2), 114-128. http://dx.doi.org/10.1177/000841749606300204.

Townsend, E. (1997a). Occupation: potential for personal and social transformation. JOS, 4(1), 18-26. http://dx.doi.org/10.1080/14427591.1997.9686417.

Townsend, E. (1997b). Inclusiveness: a community dimension of spirituality. Canadian Journal of Occupational Therapy, 64(3), 146-155. http://dx.doi.org/10.1177/000841749706400311. 
Townsend, E. (1998). Occupational therapy language: matters of respect, accountability and leadership. Canadian Journal of Occupational Therapy, 65(1), 45-50. http://dx.doi.org/10.1177/000841749806500106.

Townsend, E. (2012). Boundaries and bridges to adult mental health: critical occupational and capabilities perspectives of justice. JOS, 19(1), 8-24. http://dx.doi.org/10.1080/14427591.2011.639723.

Townsend, E., Langille, L., \& Ripley, D. (2003). Professional tensions in client-centered practice. AJOT, 57(1), 17-28. http://dx.doi.org/10.5014/ajot.57.1.17.

Tricco, A. C., Lillie, E., Zarin, W., O’Brien, K. K., Colquhoun, H., Levac, D., Moher, D., Peters, M. D. J., Horsley, T., Weeks, L., Hempel, S., Akl, E. A., Chang, C., McGowan, J., Stewart, L., Hartling, L., Aldcroft, A., Wilson, M. G., Garritty, C., Lewin, S., Godfrey, C. M., Macdonald, M. T., Langlois, E. V., Soares-Weiser, K., Moriarty, J., Clifford, T., Tunçalp, Ö., \& Straus, S. E. (2018). PRISMA Extension for Scoping Reviews (PRISMA-ScR): checklist and Explanation. Annals of Internal Medicine, 169(7), 467-473. PMid:30178033. http://dx.doi.org/10.7326/M18-0850.

VanLeit, B. (1998). Adolescent social action program: involvement of occupational therapy students in an innovative health promotion program. Occupational Therapy in Health Care, 11(3), 29-37. PMid:23948044. http://dx.doi.org/10.1080/J003v11n03_03.

Walsh, S. (2016). Learning from stories of mental distress in occupational therapy education. The Journal of Mental Health Training, Education and Practice, 11(4), 220-233. http://dx.doi.org/10.1108/JMHTEP-02-2016-0010.

Walsh, S., \& Pollard, N. (2019). 'Seeing the bigger picture': a post-graduate online learning community facilitates political competence for occupational therapists. Journal of Further and Higher Education, 44(7), 1-13. http://dx.doi.org/10.1080/0309877x.2019.1629397.

Wilding, C., \& Whiteford, G. (2007). Occupation and occupational therapy: knowledge paradigms and everyday practice. Australian Occupational Therapy Journal, 54(3), 185-193. http://dx.doi.org/10.1111/j.1440-1630.2006.00621.x.

Wilding, C., \& Whiteford, G. (2008). Language, identity and representation: occupation and occupational therapy in acute settings. Australian Occupational Therapy Journal, 55(3), 180-187. PMid:20887460. http://dx.doi.org/10.1111/j.1440-1630.2007.00678.x.

Wright, R. (1998). Research pathways for occupational therapists: taking our own road. British Journal of Occupational Therapy, 61(9), 418-422. http://dx.doi.org/10.1177/030802269806100910.

Zubriski, S., Norman, M., Shimmell, L., Gewurtz, R., \& Letts, L. (2020). Professional identity and emerging occupational therapy practice. Canadian Journal of Occupational Therapy, 87(1), 63-72. PMid:31426653. http://dx.doi.org/10.1177/0008417419870615.

\section{Contribuiçáo dos Autores}

Magno Nunes Farias e Roseli Esquerdo Lopes foram responsáveis pela concepção, redação e revisão do texto e aprovaram sua versão final.

\section{Fonte de Financiamento}

CAPES - Coordenação de Aperfeiçoamento de Pessoal de

Nível Superior -, código 001, e CNPq - Conselho

Nacional de Desenvolvimento Científico e Tecnológico.

\section{Autor para correspondência}

Magno Nunes Farias

e-mail: magnonfarias@hotmail.com

\section{Editora de seçáo}

Profa. Dra. Marta Carvalho Almeida 